Naturwissenschaften 78, 419-422(1991) (C) Springer-Verlag 1991
0028104291001076

\section{Seasonal Change in the Temporal Organization of Wheel-Running Activity of the European Hamster, Cricetus cricetus}

F. Wollnik, A. Breit and D. Reinke

Fakultät für Biologie der Universität, W-7750 Konstanz, FRG

European hamsters, like many other hibernators, show pronounced annual fluctuations in reproduction, body weight, and food intake. Together with the hibernation pattern these functions are primarily dependent on the photoperiod $[1,2]$. In this paper we demonstrate that a dramatic annual change in the temporal organization of locomotor activity goes hand in hand with the seasonal cycle of reproduction. Activity levels increased when the animals entered reproductive conditions, which occurs naturally in spring and early summer. During the $2-3$ months of reproduction, a well-defined activity rhythm was observed. During the rest of the year, the level of activity was dramatically reduced and almost no rhythmic organization was detected. The question arising from these observations is whether the loss of temporal organization reflects a weakening or arrhythmia of the underlying pacemaker or whether it is due to an uncoupling of the overt activity rhythm from the central clock. 

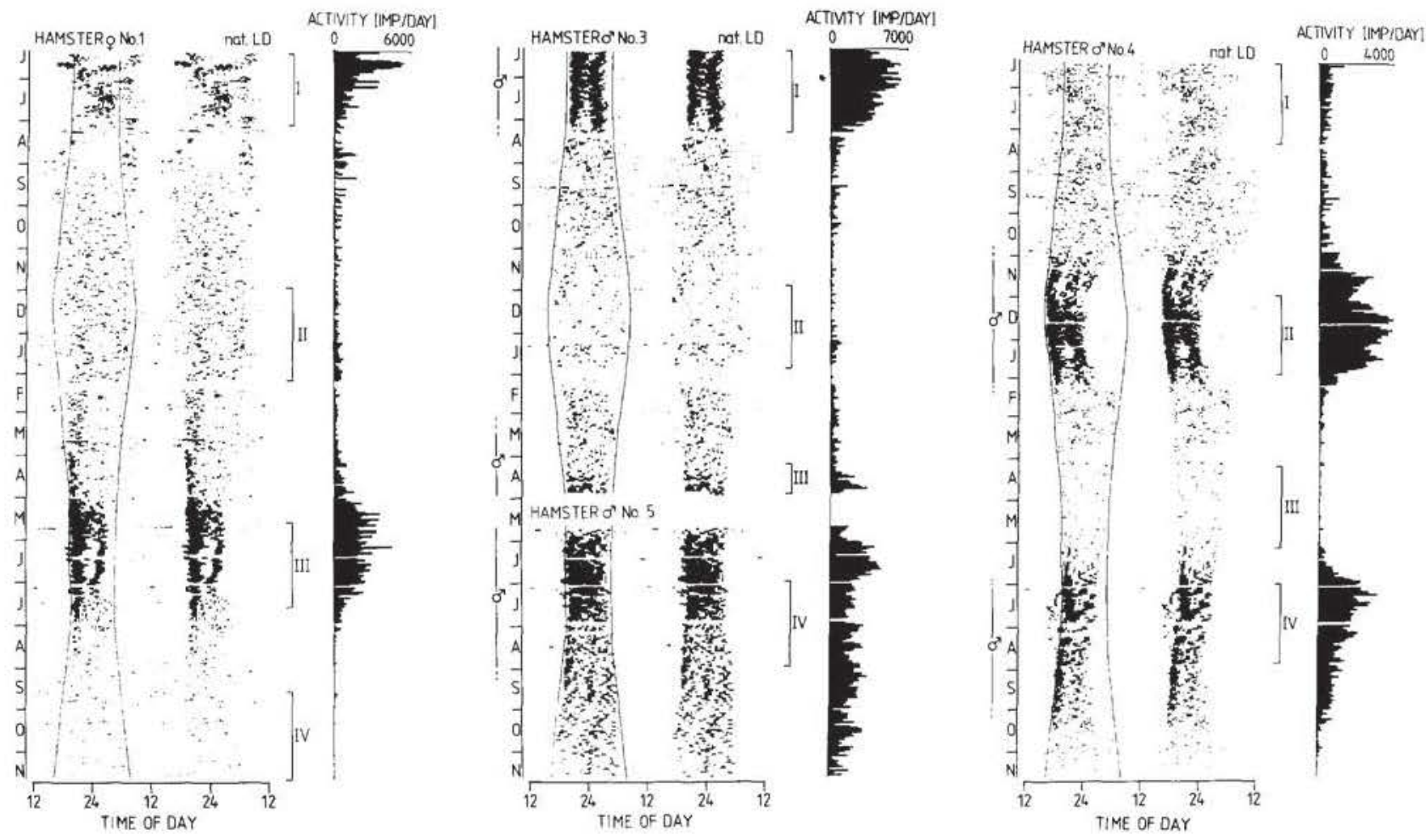

Fig. 1. Recordings of wheel-running activity of four European hamsters ( $९:$ No. $1 ;$ o $^{*}$ : No. 3 , $4,5)$ kept under natural lighting conditions for a period of 18 months. For clarity, the records are shown as double plots with successive days plotted from top to bottom on a 48 -h scale. Empty lines indicate missing data. The seasonal change of the photoperiod is expressed in the left half of the activity plot by two curved lines representing times when light was $100 \mathrm{~lx}$ at cage top level. Periods of reproductive conditions of the male hamsters are indicated at the left of each record. Numbered brackets on the right of each record refer to the respective chi-square periodograms shown in Fig. 2. Each activity record ist accompanied by a histogram showing the level of activity, given in the number of wheel-induced impulses per 24-h period

Adult European hamsters (Cricetus cricetus; 2 o, 3 o ) were obtained from a breeding colony at the Central Animal Laboratory. Medical School of Hannover, FRG, where they had been raised under long-day conditions ( $16 \mathrm{~h}$ of light per $24 \mathrm{~h}, \mathrm{LD} 16: 8)$ at $20 \pm 1{ }^{\circ} \mathrm{C}$. In Konstanz, the animals were housed in an animal room under standardized environmental conditions with a natural lighting regime. They were kept individually in polyethylene cages $(35 \times 55 \times$ $20 \mathrm{~cm})$ equipped with a nest box $(13 \times$ $27 \times 15 \mathrm{~cm})$ and a running wheel (diameter $35 \mathrm{~cm}$, width $10 \mathrm{~cm}$ ). Illumination at cage top level was measured continuously during the experiment with a lux meter. Wheel-running activity was measured with an online computer system from June 13, 1989 to November 20, 1990 for a total of 524 days. Unfortunately, one male hamster (HAM3) died at the end of April 1990. It was replaced by a litter mate that had been kept in the same animal room since the beginning of the experiment, however, without being measured. As described elsewhere [3], activity data were stored in 5-min bins for evaluation with different types of statistical analyses. Chi-square periodogram analysis [4] was used to verify the presence of rhythmicity. Every 3 weeks, the animals were weighed and the reproductive status of the males was monitored by testis palpation under light ether anesthesia, while that of the females was monitored by examining vaginal dilation.

During the 18 months of experiments, all hamsters showed dramatic changes in the intensity and rhythmic organization of their wheel-running activity (Fig. 1). In the first summer (June/July), three animals $\left(2 \circ, 1 \circ^{\circ}\right)$ displayed well-defined activity rhythms that were clearly synchronized with the natural LD cycle. Chi-square perio- dogram analysis revealed significant peaks at $24 \mathrm{~h}$ (Fig. 2; HAM1/I, HAM3/I). During autumn and winter, activity levels were low and the rhythmic organization had disappeared (Fig. 2; HAM1/II, HAM3/II). In spring and early summer, activity levels had risen again and a strong activity rhythm reappeared (Fig. 2; HAM1/III, HAM3/III). When HAM3 died at the end of April it was replaced by a litter mate (HAM5) as mentioned above. This animal also showed a strong and coherent activity rhythm during early summer (HAM5/IV). The other male hamster (HAM4) showed a different pattern of seasonal changes. At the beginning of the experiment, it had a low activity level and no significant 24-h rhythm (Fig. 2; HAM4/I). However, an increase in the intensity of wheelrunning activity and entrainment to the light-dark dycle became evident during the 3-month period from November to January (Fig. 2; HAM4/II). The level of activity was low again from February to May and high again from June to September accompanied by a decreased and increased rhythmic organization of the activity pattern, respectively (Fig. 2; HAM4/III and IV).

We found that the activity pattern of the males was clearly correlated with the reproductive status. A well-defined 

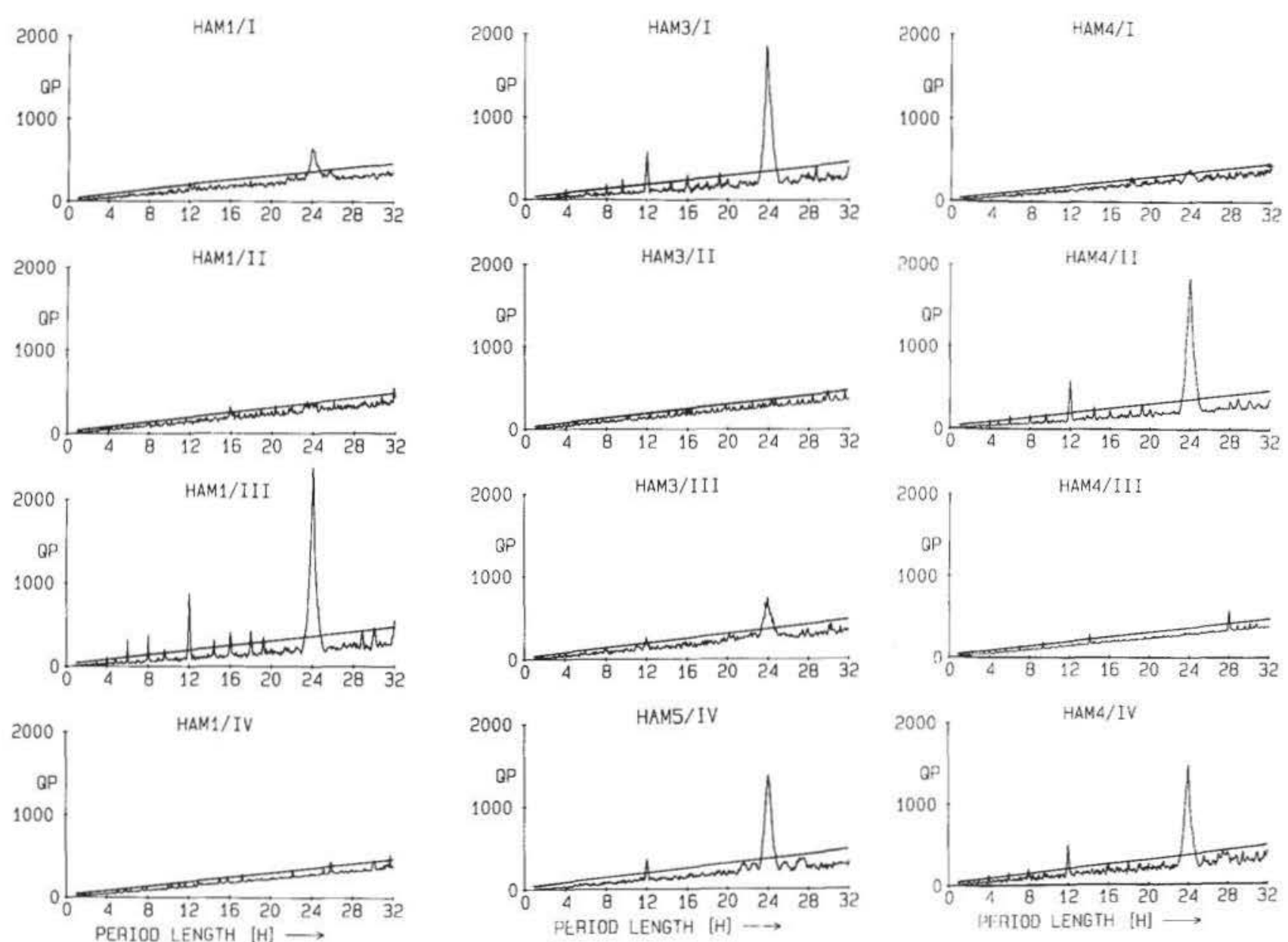

Fig. 2. Chi-square periodogram analyses for various parts of the activity recordings of Fig. 1. Periodograms were actually calculated for 21-day intervals, but are representative for the larger intervals indicated by the respectively numbered brackets in Fig. 1. The slanted line indicates the level of significance $(p<0.01)$ according to [4]

activity rhythm was observed only after the animals had entered reproductive conditions. In contrast, at the beginning of reproductive quiescence activity levels dropped and the activity pattern became more and more scattered. The reproductive status of the females was monitored only by visual inspection instead of directly by vaginal smears because the daily handling of the animals would have disturbed the activity pattern. Nevertheless, detailed analysis of the activity plots revealed a modulation of activity onset and intensity every 4 days during periods of increased rhythmic activity (Fig. 1; HAM1/III). This 4-day pattern probably reflects estrous correlated modulations similar to those described for golden hamsters [5] and rats [6, 7]. The result of this study indicate that seasonal changes in the reproductive status of the European hamster cause dramatic changes in the rhythmic pattern of wheel-running activity. The European hamster is a seasonal breeder for which it is known that photoperiod is one of the seasonal cues inducing changes in gonadal function. Under natural conditions, reproduction occurs during early spring and summer. Short day length in autumn (less than $15.5 \mathrm{~h}$ of light per $24 \mathrm{~h}$; [1]) induces a drop in gonadal function which is necessary for entering hibernation. The regrowth of the gonads occurs spontaneously by the end of the winter when the animals are still in their burrows. However, the photoperiodic regulation of the annual cycle appears to be more complex in the European hamster than in other hamster species. For example, it has been reported that in some European hamsters gonadal regression oc- curs spontaneously under long photoperiods $[8,9]$. In the present study, one male (HAM4) had also atrophied gonads in the beginning despite the fact that it had been kept under long photoperiods. However, gonadal recrudescence occurred spontaneously in November, i.e., under decreasing photoperiods, and from then on the reproductive cycle was synchronized to the natural year. This example suggests that the reproductive cycle of the European hamster is not exclusively determined by photoperiodic conditions but may also be regulated by an endogenous circannual rhythm.

Although the reproductive status is clearly correlated with the activity rhythm, no direct causal relationship has been found yet. There is substantial evidence that gonadal steroids affect parameters of activity rhythms in other rodents [10]. However, these steroid-induced modulations of the activity pattern appear minor compared to those seen in the European hamster. Drastic changes in daily activity patterns have been reported only for some species of 
the subfamily Microtinae, whose activity is predominantly nocturnal during summer and diurnal or crepuscular during winter $[11,12]$.

When interpreting the results of the present study one has, of course, to consider that wheel-running activity represents only part of the behavioral repertoire of an animal. According to various authors, it reflects mostly foraging activity outside the burrow [13, 14]. To show that other types of behavior undergo similar seasonal changes would require to record, for instance, activity inside the nest box or food and water intake. Preliminary results of a study measuring overall activity and deep body temperature of European hamsters in an outdoor enclosure indicate that both parameters undergo even more dramatic changes than wheel-running activity. They show a well-defined daily rhythm during the reproductive period in summer and a completely arrhythmic pattern during sexual quiescence in autumn and winter. During the latter half of the year, short bouts of activity were found to be randomly distributed over the 24$h$ period of a day. A similar loss of circadian rhythmicity at the beginning of the hibernation season has been described for locomotor activity in the Turkish hamster [15] and for pineal melatonin formation in the golden hamster [16]. A complete loss of the pineal melatonin rhythm has also been reported for the European hamster, however, in this case occurring during late summer [17].

The obvious question arising from this investigation is whether the observed loss in the temporal organization during reproductive quiescence reflects a weakening or even arrest of the underlying pacemaker or whether it is due to an uncoupling of the overt activity rhythm from the central clock. We plan to further investigate the functional state of the circadian timing system during seasons of reproduction and hibernation using the European hamster as a promising animal model.

We thank R. Hellmann for technical assistance and S. Küsters and R. Gosert for preparation of the figures. This research was supported by DFG research grant Wo 354/3-1 to F. W.

Received April 19, 1991

1. Canguilhem, B., Vaultier, J.-P., Pévet, P., Coumaros, G., Masson-Pévet, M., Bentz, I.: J. Comp. Phyiol. A 163, 549 (1988)
2. Canguilhem, B., Masson-Pévet, M., Koehl, C., Pévet, P., Bentz, I.: Comp. Biochem. Physiol. 89A, 575 (1988)

3. Wollnik, F.: Experientia 47, 593 (1991)

4. Sokolove, P. G., Bushell, W. N.: J. Theor. Biol. 72, 131 (1978)

5. Fitzgerald, K., Zucker, I.: Proc. Nat. Acad. Sci. USA 73, 2923 (1976)

6. Albers, H. E., Gerall, A. A., Axelson, J. F.: Physiol. Behav. 26, 21 (1981)

7. Wollnik, F., Turek, F. W.: ibid. 43, 389 (1988)

8. Darrow, J. M., Duncan, M. J., Bartke, A., Bona-Gallo, A., Goldman, B. D.: J. Comp. Physiol. A 163, 339 (1988)

9. Masson-Pévet, M., Pévet, P., VivienRoels, B.: J. Pineal Res. 4, 79 (1987)

10. Turek, F. W., Gwinner, E., in: Vertebrate Circadian Systems. Structure and Physiology, p. 173 (J. Aschoff, S. Daan, G. Groos, eds.). Berlin: Springer 1982

11. Hoogenboom, I., Daan, S., Dallinga, J. H., Schoenmakers, M.: Oecologia (Berl.) 61, 18 (1984)

12. Rowsemitt, C. N.: Physiol. Behav. 37, 797 (1986)

13. Rusak, B.: J. Biol. Rhythms 1989, 121

14. DeKock, L. L., Rohn, I.: Z. Tierpsychol. 29, 180 (1971)

15. Pohl, H.: Experientia 43, 293 (1987)

16. Vaněček, J., Janský, L., Illnerová, H., Hoffmann, K.: Comp. Biochem. Physiol. 80A, 21 (1985)

17. Pévet, P., Vivien-Roels, B., MassonPévet, M., Steinlechner, S., Skene, D., Canguilhem, B.: J. Pineal Res. 6, 233 (1989) 